\title{
Exploration of English Application Based on Information Technology
}

\author{
Xiaofang Luo ${ }^{1, \text { a, }}$, Hongxu Fei ${ }^{2, b}$ \\ ${ }^{1}$ Zhuhai College of Jilin University; Zhuhai, Guangdong, China \\ ${ }^{2}$ Zhuhai Technical School; Zhuhai, Guangdong, China \\ a12032554@qq.com, bfeihongxu881@163.com \\ *Xiaofang Luo: 12032554@qq.com
}

Keywords: Application, information technology, English learning

\begin{abstract}
To explore an overview of current English apps, taking the AppStore application and the app related to English education in educational applications as an example, the communication process and mode of English education App are studied. According to the knowledge construction process and the behavior of learning learned by the user with the app, the role and effect of such an app are analyzed. It briefly describes and analyzes the user's need to use the app media, and analyzes the app's communication effect in combination with the user's specific behavior in the English learning process. The research on app media communication process and mode can deepen the understanding of users to use app to learn English. The analysis of the effect helps to further evaluate the app's role in English education for users, thus helping developers to develop apps that are more conducive to English learning. The English education app is divided into topic independent and comprehensive, which highlights the guiding role of the app learning path. For the four major environments of English learning, the educational communication mode of app is constructed. The study found that some apps have the context, collaboration, and conversational conditions of constructivist learning, but some apps still lack the emphasis on the learning process. Some learning behaviors or effects vary between ages and genders.
\end{abstract}

\section{Introduction}

In recent years, with the rapid development of the Internet and mobile information technology, mobile media has become an important communication tool in the new media era, and it has been widely infiltrated into people's lives. Teenagers are the main body of mobile phones, their daily life, work, study, and interpersonal relationships are closely related to mobile phones. The APPs of all kinds of functions are very popular among college students, and the penetration rate among them is quite high. At the same time, as the main recipient of new things, their acceptance and learning of different APPs is also very fast.

Informal learning is relative to formal learning. Formal learning mainly refers to academic education and job skills training in schools. Informal learning refers to learning behaviors that occur at the place and time of informal learning. Learners gain knowledge transfer and knowledge penetration through non-teaching social interactions. It is a learning behavior that is managed and responsible by learners. The concept of informal learning for users to access education is no longer limited to the specific time and space of traditional classrooms, nor does it limit the way users learn. Internet technology and mobile smart devices provide convenience and a variety of functions for informal learning.

Rich online educational resources provide more learning materials support for informal learning. Mobile smart devices such as mobile phones and tablets rely on the Internet to easily access these learning materials in informal learning. The educational app is a package of educational information that is presented to learners in digital form. Learning by mobile communication technology and mobile terminal equipment can be called mobile learning. Mobile learning is very common in daily life. It even becomes a way of life. For example, people can freely choose content and control the progress of learning through the English learning software on the mobile phone. Informal learning 
is an idea about education and learning. Mobile learning is characterized by the mobility and convenience of learning methods. Mobile learning breaks the limitations of face-to-face, fixed and universalized communication activities of education information, and satisfies the needs of learners' self-learning and free learning to a certain extent. Diverse forms of learning can meet the learning needs of different learners in the context of today's Internet age, while also creating new forms of learning and opportunities for users.

\section{Literature review}

In the literature, it is found that although there are few studies on English education apps, there are many studies on English education. Turki et al. (2017) pointed out that more and more mobile devices are involved in educational scenes in the emergence stage, especially the iPad has even become an innovation in education reform. However, the actual consumption stimulus and the educational value of the app in the expectation are not necessarily satisfactory. From the aspect of design and content, it is discussed how to improve the educational potential of the iPad [1]. Li (2018) pointed out the influencing factors and guiding ideology of the educational potential of current and future educational apps, the design and use of educational apps are discussed [2]. Liu (2017) tried to set a more efficient apps standard for evaluating and screening based on the principle of "learning science" [3]. Sun et al. (2017) believed that the educational value index is related to whether the app provides users with open content and users use more difficult functions independently based on qualitative and quantitative analysis [4]. Liu et al. (2018) hoped that the user's learning is a "happy learning" state and education will reinvigorate the charm of the game [5]. Yao (2017) used educational games as a tool to assist teaching and combined traditional teaching methods to develop English education [6]. Cavus (2016) believed that educational games can bring rich emotional materials to English learning. It integrated sound into the teaching and learning process, stimulating learning motivation and cultivating a wide range of user skills [7]. Ma (2017) believed that the English application method is not only conducive to achieving teaching goals and improving learning enthusiasm, but also improving students' comprehensive skills in computer operation, cooperation and communication [8].

\section{Methodology}

Six aspects of coding design and statistical analysis are carried out through the content and form of 100 eligible English education apps. Therefore, the understanding of the content composition of English education App and the path of educational information dissemination is deeper. On this basis, interviews are conducted with two families using English education apps. The focus of the interviews is to observe and analyze the learning process of app users. Finally, with the help of the educational communication process of science of educational communication and the related theories of two modes of communication, the mode of communication of English education App is explored. Research on the spread effect of app. Starting from the perspective of constructivist learning, the learning situation, collaborative learning, and conversational learning of English education apps are analyzed. Combined with the case to explain how the app assists the user to learn, through the questionnaire survey method, the basic situation of the user's use of the medium and the preference for the learning situation are statistically analyzed, and the user's collaboration and conversational learning are analyzed. The process of cognitive learning of users is explained by means of multimedia learning cognitive theory. Finally, the questionnaire survey is used to analyze the user's use of the app to listen to English, read English, write English, memory and knowledge transfer. Whether the user has age difference or gender difference in some learning behaviors is analyzed. 


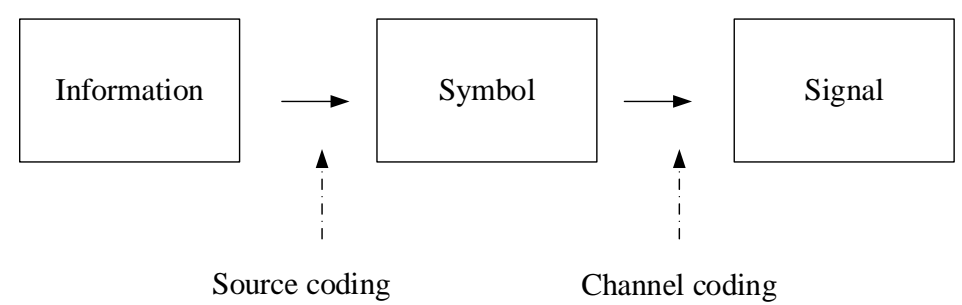

Figure 1 Coding process.

As shown in the encoding process of Figure 1, encoding refers to the transmitting end converting information into a transmittable signal, including source coding and channel coding.

Table 1 Human-computer interaction form

\begin{tabular}{|c|c|c|c|c|c|}
\hline & Frequency & Percentage & $\begin{array}{c}\text { Effective } \\
\text { percentage }\end{array}$ & $\begin{array}{c}\text { Cumulative } \\
\text { percentage }\end{array}$ \\
\hline Effective & $\begin{array}{c}\text { The operation of } \\
\text { simple gesture }\end{array}$ & 83 & 83 & 83 & 83 \\
\cline { 2 - 6 } & $\begin{array}{c}\text { Support for the } \\
\text { operation of } \\
\text { complex gesture }\end{array}$ & 17 & 17 & 17 & 100 \\
\cline { 2 - 6 } & Total & 100 & 100 & 100 & \\
\hline
\end{tabular}

It can be seen from Table 1 that $17 \%$ of the complex gestures can be inferred to some extent that the human-computer interaction of the current app development is mostly based on clicks, that is, viewing content is dominant, and there are fewer opportunities for hands-on.

Table 2 The form of responding to an error or not responding to feedback

\begin{tabular}{|c|c|c|c|c|c|}
\hline & Frequency & Percentage & $\begin{array}{c}\text { Effective } \\
\text { percentage }\end{array}$ & $\begin{array}{c}\text { Cumulative } \\
\text { percentage }\end{array}$ \\
\hline Effective & No feedback & 60 & 60 & 60 & 60 \\
\cline { 2 - 6 } & $\begin{array}{c}\text { Sound and screen } \\
\text { prompt }\end{array}$ & 34 & 34 & 34 & 94 \\
\cline { 2 - 6 } & $\begin{array}{c}\text { Screen but no sound } \\
\text { prompt }\end{array}$ & 6 & 6 & 6 & 100 \\
\cline { 2 - 6 } & Total & 100 & 100 & 100 & \\
\hline
\end{tabular}

Table 3 Form of response to correct feedback

\begin{tabular}{|c|c|c|c|c|c|}
\hline & Frequency & Percentage & $\begin{array}{c}\text { Effective } \\
\text { percentage }\end{array}$ & $\begin{array}{c}\text { Cumulative } \\
\text { percentage }\end{array}$ \\
\hline Effective & No feedback & 59 & 59 & 59 & 59 \\
\cline { 2 - 6 } & $\begin{array}{c}\text { Sound and screen } \\
\text { prompt }\end{array}$ & 40 & 40 & 40 & 99 \\
\cline { 2 - 6 } & $\begin{array}{c}\text { Sound but no screen } \\
\text { prompt }\end{array}$ & 1 & 1 & 1 & 100 \\
\cline { 2 - 6 } & Total & 100 & 100 & 100 & \\
\hline
\end{tabular}

In this article's statistics, about $40 \%$ of the app responded to the operation, as shown in Table 2 and Table 3.

\section{Results}

Based on the current status of the app, some apps embody the role of situation, collaboration, and conversation in constructivist learning. However, at this stage, there are still many apps that do not integrate the meaning constructing learning strategy of the constructivist learning concept into the app's research and development. Focusing solely on the collection and packaging of educational resources, it is easy to form a teaching idea of instilling knowledge based solely on the listing of educational resources. App from the perspective of constructivist learning and the cognitive theory 
of multimedia learning must pay attention to the learning and cognitive process. Developers should focus on how education goals and educational information can be used to guide users in building knowledge. In addition, the educational goals should be clear, the learning path and learning methods should be clear, and users should not be able to start.

The research status and background of the English education app are elaborated, and the relevant theories are combed. Based on the current research on app research perspective and content depth, the need to analyze the content of English education App is established, and it also lays the foundation for the full text.

The English education App is defined. According to the complexity of the educational goals, it is divided into the theme independent App and the comprehensive App. The "learning path" of the app is defined and divided into a free learning path and a mandatory learning path. It can be further subdivided according to the complexity of the different learning paths.

Combined with the statistical differentiation of the sample app, the basic use, consumption, and interaction of the app are explained. The characteristics of the current English education App are summarized as follows: digitalization is low, quality is polarized; content contextualization and gamification; content homogenization, lack of novel form. The future development trend of English education App is that with the development of digital technology, the digital education of app will further blur the boundaries between informal education and formal education and become a mix learning method.

Based on the basic mode of education communication, the educational communication mode of English education App is sorted out. The focus of users in the educational environment, the Internet environment, the classroom environment, and the family environment is highlighted, and the path of App information dissemination is clarified. Based on the statistics of sample apps, four propagation factors were analyzed in detail. The content of the app "learning path" is combed. The role of the learning path is to clarify the order of interaction between children and educational information, including difficulty level and learning order, which is one of the manifestations of teaching methods. The learning path is the skeleton of the children's learning environment, which affects the learning efficiency to some extent. In the analysis of the "situation" elements of APP, the purpose, restore, story, fun and functionality of the app "situation" are analyzed in detail.

At present, the app's copyright awareness is relatively lacking, and there are many unauthorized or ripped app resources. Developers should fully curb this bad business behavior and fully respect the labor results of educators and developers. There are two obvious weaknesses in the education app. First, the technical difficulties of learning feedback and learning evaluation. For example, the specific pronunciation can't be corrected for the user, and the built-in evaluation system lacks personalized speech evaluation and processing. Second, the learning method is rigid. For example, the memory link of the user's words generally has a word card game, which is essentially a mechanical trial and error learning method. This learning method has low development cost but can't highlight the view of constructivist learning. Developers can design corresponding contexts and conversational content for vocabulary to help users construct a multimedia environment for meaningful learning, rather than the rote mode of "the answer is correct, go to the next one, the answer is incorrect, continue to try ", and it is also not the hard mode of continuous Chinese and English translation in some English video tutorials.

\section{Conclusion}

The research object is an English education app. First of all, the research object has been researched and analyzed. From the perspective of educational communication, the educational communication model of English education App is sorted out and the elements of "educational information", "educator", "educatee" and "transmission noise" are analyzed. Then from the perspective of constructivist learning, the effects of "situation", "collaboration" and "conversation" elements on learning are analyzed, and the cognitive process of users using app learning is analyzed from the perspective of cognitive construction of multimedia learning. Finally, combined with the questionnaire survey, the effect of English education App is analyzed. 
The exploration of the content and effect of English education App may be a reference for developers. However, due to the limited research capacity, many deficiencies have also been exposed. For example, the study method of learning effects is not a scientific method for assessing and measuring educational effects. Therefore, the reference effect is very limited. Secondly, it is impossible to observe and analyze the actual situation of more users in more family environments. In the future study and life, relevant research will be further concerned and the research will be deepened.

\section{References}

[1] Turki, I., Laignel, B., Kakeh, N., Chevalier, L., and Costa, S. (2017) A new hybrid model for filling gaps and forecast in sea level: application to the eastern english channel and the north atlantic sea (western france). Ocean Dynamics, 65(4), 1-13.

[2] Li, M. (2018) Investigation on application of association rule algorithm in english teaching logistics information. Cluster Computing (4), 1-7.

[3] Liu, K. (2017) Design and application of an online english self-learning platform. International Journal of Emerging Technologies in Learning, 12(8), 4.

[4] Sun, Y., Jiang, X., Sun, Y., Jiang, X., Sun, Y., and Jiang, X. (2017) The design and application of english pronunciation training software based on android intelligent mobile phone platform. Revista De La Facultad De Ingenieria, 32(5), 756-765.

[5] Liu, X., and Zhang, J. (2018) Application of computer distance education in practical english writing teaching. International Journal of Emerging Technologies in Learning, 13(4), 71.

[6] Yao, S. (2017) Application of computer-aided translation in english teaching. International Journal of Emerging Technologies in Learning, 12(8), 105-117.

[7] Cavus, N. (2016) Sciencedirect development of an intellegent mobile application for teaching english pronunciation. Procedia Computer Science, 102, 365-369.

[8] Ma, L. (2017) Application research of computer software in contributing effectively to students learning english. C E Ca, 42(4), 1444-1449. 